\title{
EFEITOS DA POLUIÇÃO ATMOSFÉRICA (LITORÂNEA E INDUSTRIAL) EM ISOLADORES DA REDE ELÉTRICA DA REGIÃO METROPOLITANA DE SALVADOR
}

\author{
Kleber Franke Portella ${ }^{*}$, Fernando Piazza, Paulo Cesar Inone e Sebastião Ribeiro Jr. \\ Instituto de Tecnologia para o Desenvolvimento, CP 19067, 81531-980 Curitiba - PR, Brasil \\ Mário Seixas Cabussú, Dailton Pedreira Cerqueira e Cleuber Sobreira da Silva Chaves \\ Companhia de Eletricidade do Estado da Bahia, Granjas Rurais, Av. Pres. Vargas, s/n, 41290-000 Salvador - BA, Brasil
}

Recebido em 26/3/07; aceito em 13/8/07; publicado na web em 26/2/08

\begin{abstract}
ATMOSFERIC POLLUTION (COASTAL AND INDUSTRIAL) EFFECTS ON ELECTRIC ENERGY DISTRIBUTION INSULATORS IN SALVADOR, BRAZIL, METROPOLITAN REGION. The performances of eight kinds of insulators from electrical distribution lines in Salvador-BA, Brazil, were evaluated considering the chemical and physical local environmental pollution. The parameters that were chosen as characteristic for the insulators' properties were leakage current and partial electrical discharge. A data storage processing system and a communication link to the lab were built for data acquisition. The results show that the main contribution to the poor performance of the insulators is settleable magnetite particulate matter on the insulator in addition to the long term wetness time, $t_{4}$.
\end{abstract}

Keywords: electrical insulator; environmental pollution; physicochemical characterization.

\section{INTRODUÇ̃̃O}

Salvador é uma cidade de clima quente e úmido, tipicamente tropical, com cerca de $2.466 \mathrm{~h}$ anuais de sol, ventilada (ventos anuais com velocidade média de $2,2 \mathrm{~m} / \mathrm{s}$ ) e uma temperatura média anual de $25{ }^{\circ} \mathrm{C}(76 \mathrm{~F})$. É considerada uma das cidades mais ensolaradas do mundo, com umidade média anual da ordem de $81 \%$, tendo a vantagem de ser cercada pelo mar em 3 de seus lados ${ }^{1}$. Estas condições climáticas são ideais para a atração turística, mas, extremamente prejudiciais aos materiais de engenharia, principalmente nos locais onde há, concomitantemente, poluição industrial. Assim, têm-se como desvantagens, em boa parte das regiões analisadas: ambiente propício à corrosão ou degradação dos materiais como os metálicos, pela instauração de um tempo de superfície úmida $(\mathrm{t})$ elevado $(\approx 4.000 \mathrm{~h} / \mathrm{ano})$, neste caso, classificado pela NBR 14643/01 ${ }^{1}$, como $t_{4}$, ou seja, de alta corrosividade ambiental $\left(\mathrm{C}_{4}\right)$; altas taxas de salinidade e material particulado de dureza elevada, devidos aos ventos predominantes em direção ao continente, podendo causar corrosão atmosférica pelos íons cloretos e sulfatos e, também, erosão por abrasão das superfícies dos materiais e, alta taxa de radiação solar, com valor médio $>2.400 \mathrm{~h} / \mathrm{ano}$, o que amplia a possibilidade de degradação dos materiais, principalmente, os poliméricos ${ }^{1}$.

\section{Isoladores $^{2}$}

Os isoladores para linhas de alta e baixa tensão são dispositivos que têm a função de dar suporte mecânico rígido ou flexível para os condutores elétricos ou equipamentos e mantê-los isolados do aterramento, de outras partes condutoras e das próprias estruturas de suporte. Podem ser constituídos de ferragens, porcelana, vidro, polímero ou material compósito e cimento, para manter as partes integradas (ferragens e saias).

Para realizar as funções mecânicas e elétricas desejadas, há uma série de condições técnicas exigíveis.

\footnotetext{
*e-mail: portella@lactec.org.br
}

\section{Isoladores de porcelana}

Atualmente, o isolador de porcelana processado via úmida é a forma de isolação elétrica mais utilizada no sistema de distribuição e transmissão de energia. Seu desenvolvimento teve início a partir do isolador tipo pino, usado em linhas de comunicação, mas, com as características elétricas melhoradas, tais como em relação à sua seção transversal e ao diâmetro da saia que foram ampliados para aumentar a distância de escoamento. Mesmo assim, tais mudanças só foram efetivas para baixas tensões elétricas. Para tensões de $69 \mathrm{kV}$ e superiores foi introduzida a montagem de isoladores do tipo multicone cimentados, os quais eram muito grandes, pesados e impraticáveis para a transmissão de energia acima de $100 \mathrm{kV}$. Além destas características físicas e dimensionais constataram-se problemas de perfuração elétrica devido à fissuração da porcelana, cuja causa estava ligada à expansão da camada cimentante entre esta e a ferragem. Em conseqüência destes problemas houve na Europa, principalmente, o desenvolvimento de sistemas de isolamento em uma única peça ou bastão, enquanto na América do Norte o desenvolvimento foi para um isolador de suspensão do tipo cadeia. Atualmente, bastões de porcelana de diversos metros de comprimento são produzidos para uso em sistemas de transmissão de até $400 \mathrm{kV}$.

\section{A porcelana como dielétrico}

As propriedades elétricas da porcelana são dependentes de um grande número de parâmetros, entre os quais se destacam a composição química, a espessura, as condições superficiais e a temperatura de sinterização. Também, a espessura da amostra tem efeito na rigidez dielétrica, a qual diminui exponencialmente com o seu acréscimo, em conseqüência do aumento da quantidade de defeitos microestruturais (vazios e formas irregulares de grãos). Normalmente, a rigidez dielétrica da porcelana diminui com o teor de poros, mas para a mesma porosidade, quanto menor esta distribuição, maior a rigidez dielétrica. Em termos de composição química, a porcelana fabricada com grande quantidade de quartzo não-dissolvido tem, frequientemente, fissuras periféricas entre a fase vítrea e os próprios grãos de quartzo. 


\section{Isoladores de vidro}

No final de 1880, quando as primeiras linhas de transmissão foram construídas os isoladores utilizados eram de vidro, por já estarem operando em linhas telegráficas e pelas suas bem conhecidas propriedades dielétricas e mecânicas. Além disto, tinha-se a tecnologia de conformação com abundante fornecimento de matéria-prima.

Na medida em que as linhas de transmissão necessitavam atender uma maior capacidade elétrica, condutores mais pesados e vãos maiores requeriam isoladores com maior rigidez dielétrica. Em resposta, vários tipos de projetos de isoladores de suspensão apareceram usando vidro fundido como dielétrico. Todavia, os primeiros produtos fabricados não tiveram sucesso absoluto em relação ao seu desempenho elétrico e mecânico, devido aos defeitos internos comumentemente encontrados e que aumentavam a probabilidade de ruptura ou quebra sob estresse mecânico, tais como as sementes, pedras e cordas. As sementes são pequenas bolhas de gás que não são removidas durante a operação de fusão, a não ser pelo seu refinamento com produtos químicos à base de $\mathrm{Sb}_{2} \mathrm{O}_{5}$ e $\mathrm{As}_{2} \mathrm{O}_{3}$ que são adicionados ao banho para auxiliar na dissolução das mesmas; as pedras, são pequenas imperfeições cristalinas encontradas durante o período de fusão, tendo como uma das principais origens o $\mathrm{ZrO}_{2}$, que compõe a parede dos fornos refratários, e, as cordas que são inclusões amorfas que podem ser detectadas devido ao seu índice de refração que é diferente do vidro circundante, sendo resultantes da mistura inadequada de ingredientes do vidro e da homogeneização incompleta do fundido.

Na medida em que o vidro fundido é formado a partir da mistura de areia de sílica e vários óxidos minerais a sua estrutura interna, no resfriamento, passa a ser completamente não-cristalina. Embora diversas definições de vidro sejam utilizadas para descrever suas propriedades químicas, físicas e mecânicas, do ponto de vista dielétrico pode ser considerado como um eletrólito, no qual os principais portadores de carga provêm dos componentes alcalinos $\mathrm{NaOH}$ e $\mathrm{KOH}$, e cujos íons aumentam a constante dielétrica, o fator de dissipação e sua condutividade elétrica. Sob tensão em corrente contínua (DC), os pequenos íons $\mathrm{Na}^{+}$migram pelos canais da rede de sílica, podendo ocorrer o mesmo com os íons $\mathrm{K}^{+}$, mas, a uma taxa menor. Em conseqüência, pode ocorrer a acumulação destes nas sementes, pedras e cordas e sua subseqüente neutralização por íons oxigênio. Este processo é manifestado por um aumento de volume, criando um ponto de estresse mecânico localizado. Também, a condução iônica poderá gerar em uma zona estreita da estrutura os gradientes térmicos e, conseqüientemente, a sua ruptura mecânica. Em ambos os casos, ocorrerão estilhaçamentos do vidro. Estudos do fenômeno têm mostrado que a resistividade elétrica do vidro é um dos mais importantes parâmetros nos isoladores DC.

\section{Isoladores não-cerâmicos (poliméricos e compósitos)}

No final de 1950, o desenvolvimento de um isolador com peso reduzido e características elétricas e mecânicas melhores em relação aos isoladores cerâmicos convencionais foi considerado um prérequisito para as linhas de transmissão de $1000 \mathrm{kV}$. Embora o interesse na transmissão de energia em $1000 \mathrm{kV}$ tenha diminuído, a busca por isoladores mais leves continuou, de modo que o primeiro isolador não-cerâmico foi fabricado em 1959, mas com diversas falhas devido ao trilhamento e à erosão, as quais estavam relacionadas com as saias fabricadas com resina-epóxi. Poucos anos mais tarde, fabricantes europeus introduziram no mercado a primeira geração de isoladores não-cerâmicos com menor percentual de falhas. Estes isoladores tinham um núcleo composto por um bastão em fibra de vidro recoberto por saias de material polimérico e as ferragens unidas ao núcleo de diferentes maneiras.
Na mesma época, os fabricantes utilizavam vários tipos de materiais poliméricos nas saias, entre os quais se destacavam o teflon, a resina-epóxi, a borracha de silicone vulcanizada à temperatura ambiente, a borracha de silicone vulcanizada a altas temperaturas, a borracha de etileno propileno-dieno (EPDM) e o polipropileno. Alguns destes polímeros foram carregados com cargas inorgânicas, tais como a alumina triidratada (ATH) e a sílica, para obter as propriedades anti-trilhamento desejadas. As ferragens foram unidas ao núcleo de diferentes modos, os quais incluíam cola com resina-epóxi, inserção de cones e a compressão do metal no bastão. Hoje, após o desenvolvimento continuado e extensivos testes em campo e em laboratório, isoladores não-cerâmicos estão em uso para tensões de até $765 \mathrm{kV}$.

\section{O dielétrico compósito}

Consiste de núcleo e saias. Embora a qualidade do núcleo de fibra de vidro seja de grande importância no desempenho global dos isoladores não-cerâmicos, têm sido muito poucas as falhas atribuídas ao material. Similarmente, a qualidade das saias é, também, de grande importância no desempenho global dos isoladores poliméricos. Vazios entre o núcleo e as saias e entre as saias moldadas individualmente aumentam a probabilidade de falha. Estas têm ocorrido devido à fratura frágil do núcleo de fibra de vidro e à má aderência da selagem, permitindo que o mesmo entre em contato com os poluentes atmosféricos e a umidade.

A importância da avaliação dos isoladores vem do fato de corresponderem a cerca de $10 \%$ dos custos diretos de uma linha de transmissão e, indiretamente, por causarem prejuízos de grande monta ao setor elétrico, como na interrupção no fornecimento de energia ou "apagões".

A diminuição das características elétricas de um isolante pode ter como origem um aumento da passagem da corrente de fuga entre seus terminais. Este aumento se deve, principalmente, ao grau de contaminação por agentes poluentes que modificam a resistividade elétrica da sua superfície. Estas contaminações podem ser os depósitos de poeira; minerais inertes condutivos, como carbono e óxidos metálicos; e as soluções de água e sal, que acarretam comportamentos semelhantes ao de um resistor altamente variável e nãolinear (varistor), sendo, em muitos dos casos, instáveis na presença de campos elétricos. Esta corrente de fuga acaba originando calor, produtos resultantes da eletrólise e descargas elétricas.

Os principais processos de transporte e deposição de materiais nas superfícies dos isoladores e outros acessórios da rede elétrica são decorrentes de forças gravitacionais, atração eletrostática das partículas eletricamente carregadas, migração de partículas de alta permissividade para regiões de alta divergência de campo elétrico, evaporação de soluções ou suspensões e os aprisionamentos aerodinâmicos das mesmas. Estes últimos estão relacionados à forma geométrica, tamanho, densidade das partículas e, ainda, à intensidade do fluxo de ar. O isolador faz com que o fluxo de ar se divida, formando pontos de estagnação onde as partículas podem ser aprisionadas. A retirada destas partículas é auxiliada, na maioria das vezes, pela lavagem com água da chuva.

\section{Teores de contaminação $o^{2,3}$}

$\mathrm{O}$ dimensionamento de isoladores para áreas com alto grau de poluição é realizado em duas etapas, sendo, basicamente, pelo levantamento do grau de poluição do local e, pela determinação das características do isolamento.

A norma IEC $815^{2}$ indica quatro patamares de contaminação, sendo definidos em uma escala crescente que vai desde contaminação de baixo teor até a contaminação de teor crítico. Esta última é considerada para as áreas sujeitas à condução por poeiras, fumos industriais, 
depósitos condutivos, maresia ou ventos marítimos de grande velocidade e poluídos, e tem interesse direto nesta pesquisa.

A avaliação do grau de contaminação pode ser feita qualitativamente a partir de informações do desempenho dos isoladores de linhas e subestações e in situ, podendo-se utilizar as seguintes medidas: condutividade volumétrica do contaminante; densidade equivalente de depósito de sal na superfície do isolador (método ESDD); número total de surtos elétricos superficiais "flashover"; condutividade superficial e, corrente de fuga.

O método de condutividade volumétrica não fornece informações diretas sobre a frequiência e o grau de contaminação do local, sendo contrário ao método ESDD; o método do número total de "flashover" fornece informações confiáveis, somente, quando obtidas de isoladores com dimensões próximas aos utilizados em campo e que estão sujeitos aos arcos de tensões próximas às tensões de operação; os dois últimos métodos necessitam de equipamentos para armazenar informações, sendo que os efeitos de contaminação devem ser monitorados continuamente, o que os torna de custos mais elevados.

\section{Desempenho de isoladores em ambientes poluídos}

Testes efetuados sob chuva artificial com isoladores em borracha de silicone recobertos com uma camada de poluição artificial mostraram que seus desempenhos dependeram da taxa de precipitação pluviométrica ${ }^{3}$. Sob chuva forte, a resistência superficial diminuiu nos primeiros instantes, mas tornou a aumentar, rapidamente, devido à lavagem da camada de contaminação. Sob chuva leve, a resistência superficial diminuiu mais lentamente e permaneceu baixa por muito mais tempo. Finalmente, sob névoa, obtiveram-se valores mais baixos e com tendência a permanecerem constantes. A tensão suportável dos isoladores aumentou de maneira correspondente ao aumento da resistência superficial, à medida que se elevou a taxa de precipitação da chuva, devido ao efeito da lavagem superficial. Sob névoa, observou-se que a tensão suportável dos isoladores de silicone foi, em média, 20 a $70 \%$ superior à dos isoladores de porcelana e de vidro, quaisquer que fossem os teores de contaminação ${ }^{3,4}$. Foi verificado inclusive que, mesmo quando a superfície do silicone se tornou hidrofílica, a tensão suportável do isolador ainda foi superior à dos isoladores de porcelana e de vidro ${ }^{4}$.

Em testes efetuados sob chuva, porém, a suportabilidade dos isoladores de porcelana e de vidro foi igual à dos isoladores de silicone, devido à rápida lavagem da camada de poluição pela água da chuva ${ }^{5}$, que pareceu ser mais eficiente no caso dos isoladores cerâmicos. Medidas do teor de poluição realizadas por vários anos, mostraram haver, sempre, maior depósito de poluentes em isoladores de silicone em comparação aos de porcelana ${ }^{3,6}$. Este resultado foi atribuído à superfície aderente dos isoladores de silicone, devido à existência de componentes de baixo peso molecular que migraram para a superfície do material.

Testes efetuados em ambiente externo mostraram que a resistência superficial de isoladores de porcelana caiu rapidamente quando a umidade relativa do ar atingiu aproximadamente $70 \%$, ao passo que a resistência superficial de isoladores de silicone só começou a diminuir quando a umidade atingiu aproximadamente $80 \%$.

Medidas de corrente de fuga efetuadas em isoladores de silicone, porcelana e EPDM com distâncias de escoamento similares e em torno de $3700 \mathrm{~mm}$, e outro de EPDM, aqui codificado como EPDM_2 com distância de escoamento de 2032 mm, todos permanentemente energizados com $130 \mathrm{kV}$ fase-terra, em campo de teste situado na região costeira da Suécia, entre os anos de 1988 a 1995 , demonstraram que o número de picos de corrente foi sempre muito pequeno, em qualquer das faixas de valores trabalhadas. $\mathrm{O}$ isolador EPDM_2, com menor distância de escoamento que os demais, apresentou um número razoável de picos de corrente na faixa de 1 a $5 \mathrm{~mA}$. O isolador de porcelana apresentou, comparativamente, o maior número de picos de corrente de fuga entre 1 e $5 \mathrm{~mA}$, enquanto que a amostra EPDM apresentou o maior número de picos de corrente entre 5 e $25 \mathrm{~mA}$ e acima de $25 \mathrm{~mA}^{7}$.

Para cada teor de poluição há uma distância de escoamento específica em $\mathrm{mm} / \mathrm{kV}$ (fase - fase) a ser considerada, sendo maior para as maiores tensões elétricas a que o dispositivo está solicitado. Assim, por exemplo, para um baixo teor de poluentes, a distância mínima a ser considerada é de $16 \mathrm{~mm} / \mathrm{kV}$, passando para $31 \mathrm{~mm} /$ $\mathrm{kV}$ quando o teor de poluentes é crítico ${ }^{2}$.

Extensão da suportabilidade dos isoladores frente a contaminações ambientais ${ }^{5}$

Os problemas de poluição não podem ser resolvidos economicamente só pela escolha do isolador, principalmente em áreas de contaminação ambiental severas e com baixa precipitação pluviométrica, sendo que outros processos têm que ser utilizados, tais como cobertura periódica com compostos na forma de graxas; lavagem periódica e, limpeza manual com desenergização dos circuitos.

Os compostos utilizados para a cobertura da saia dos isoladores de distribuição são, principalmente, produtos derivados do silicone ou derivados de hidrocarbonetos. A espessura da camada depende da sua composição química, de suas propriedades físicas e do grau de poluição ambiental. Geralmente, para os compostos derivados de silicone a camada deve ter em torno de $1 \mathrm{~mm}$ de espessura, devendo ser maior para os compostos derivados de hidrocarbonetos. Mesmo assim, se faz necessária manutenção periódica com retirada da cobertura desgastada e reaplicações de materiais novos. As frequiências de limpeza e de recobertura dependem do grau de contaminação e das condições climáticas.

\section{Lavagem}

Dois métodos de lavagem vêm sendo utilizados na prática para remover a poluição: o uso de jatos de água fixos e portáteis, manualmente controlados. O emprego do jato fixo e automático é o método mais efetivo para minimizar o efeito da poluição, só que tem alto custo inicial de instalação, mas, baixo custo de manutenção. Os equipamentos portáteis e controlados manualmente têm custo inicial baixo e um alto custo de manutenção. São necessários cuidados especiais quanto à segurança. A eficiência da lavagem depende do desenho do isolador.

Alguns materiais abrasivos vêm sendo utilizados para limpeza de isoladores, tais como os resíduos de cortiça, porém, trazem como desvantagem a quantidade de material espalhada ou dispersa no meio ambiente se não forem utilizadas cabines para confinamento do resíduo durante a operação ou serviço ${ }^{8}$.

\section{Descargas superficiais e trilhamento elétricos em isoladores}

As descargas superficiais ocorrem, normalmente, entre o eletrodo e parte da superfície do sistema isolante. Quando o campo elétrico paralelo à superfície excede determinado valor crítico, devido a alterações na condutividade da mesma, inicia-se o processo de descargas elétricas superficiais, com a formação de trilhamento elétrico, que se propaga ao longo da direção do campo. A ocorrência do fenômeno de trilhamento elétrico até a ruptura do dielétrico pode ser descrita como ${ }^{9}$ contaminação e umedecimento da sua superfície, formando uma camada condutora com baixa resistência superficial; passagem de corrente elétrica superficial com alta dissipação de calor e perda não-uniforme da solução da camada condutora, favorecendo a formação das bandas secas; interrupção do fluxo de corrente elétrica superficial, devido à presença da banda seca; elevação da temperatura pelas descargas superficiais, causando a formação de resíduos que geram a erosão gradual; propagação da trilha de resíduo de carbono e, a ruptura completa da 
superfície do material, de maneira que o volume restante é incapaz de apresentar resistência à tensão elétrica aplicada.

\section{Distância de $\operatorname{arco}^{2}$}

Com os isoladores úmidos, partes das superfícies podem não apresentar resistência de isolamento. Nestas condições, a distância total de arco dos mesmos deve ser considerada pela soma das menores distâncias do final da saia superior até as saias subsequientes e mais a distância do final da última saia até o pino. Com o isolador limpo e seco, suas superfícies possuem resistências de isolamento plenas e a distância de arco deve ser tomada como a menor distância entre o condutor e o pino.

\section{PARTE EXPERIMENTAL}

Como estudo de caso foram consideradas a subestação de energia elétrica SE_Paripe e a rede de distribuição, RD, localizada em seus arredores até $2 \mathrm{~km}^{2}$, na Baía de Aratu, região metropolitana de Salvador, RMS.

\section{Investigação dos poluentes}

Os poluentes depositados na superfície dos isoladores (material particulado, MP_1) foram retirados com auxílio de ferramentas manuais, com posterior desagregação e homogeneização na forma de pó em almofariz.

Para a análise do material particulado em supensão no ar atmosférico na SE_Paripe (MP_2) foi utilizado um amostrador de partículas portátil, destinado a medir a concentração de partículas em suspensão no ar, segundo recomendações da norma NBR $9547^{10}$. Também, foram coletados resíduos de minérios que são periodicamente descarregados na baía de Aratu, devido a sua semelhança com os materiais particulados em suspensão e depositados sobre os isoladores da região da SE_Paripe. Este material foi codificado como MP_3.

A investigação dos poluentes, MP_1, MP_2 e MP_3, foi baseada em técnicas espectroscópicas, por microssonda analítica por energia dispersiva de raios $\mathrm{X}$, instalada no microscópio eletrônico de varredura, objetivando uma análise química elementar do depósito; difratometria de raios $\mathrm{X}$, objetivando identificar as fases químicas presentes em todos os materiais; levantamentos qualitativos do depósito, como as suas características físicas e, medidas das quantidades de poluentes ambientais do local, por intermédio da medida da salinidade e da taxa de sulfatação e do material particulado em suspensão.

\section{Propriedade ferromagnética}

A análise do material, na forma de pó, foi efetuada com auxílio de um imã usual para certificar a sua característica ferromagnética. Também foi investigada a aderência do material às saias dos isoladores, por intermédio de ferramentas manuais, sendo considerado um grau qualitativo de aderência.

\section{Composição química}

A composição química elementar, semi-quantitativa, do pó foi realizada a partir da técnica de microanálise por energia dispersiva de raios X (EDS), em equipamento de marca Edax, acoplado a um microscópio eletrônico de varredura, Philips, modelo XL 30.

As fases cristalinas presentes nas amostras de pó foram obtidas por intermédio da difratometria de raios $\mathrm{X}$. Um equipamento da marca Philips, modelo X'Pert MPD, foi utilizado para a medida. Os parâmetros de análise utilizados foram: radiação $\mathrm{CuK}-\alpha$, com comprimento de onda de $1,54184 \AA$; tensão de $40 \mathrm{kV}$; corrente de $40 \mathrm{~mA}$; varredura $2 \theta$ entre $15^{\circ}$ e $90^{\circ}$; tamanho do passo de $0,020^{\circ}$; tempo do passo de $1 \mathrm{~s}$ e velocidade de varredura de $0,020^{\circ} / \mathrm{s}$.

As distribuições granulométricas dos tamanhos médios das partículas dos pós MP_1 e MP_3 foram obtidas a partir da dispersão das mesmas em solução aquosa, sem agente dispersivo, em granulômetro a laser, marca Cilas, modelo 1024.

\section{Investigação dos poluentes atmosféricos}

Para a determinação da salinidade e da taxa de sulfatação, representadas pelo íon cloreto e pelo dióxido de enxofre, presentes no ar atmosférico, foram utilizados os métodos recomendados pela NBR 6211 e NBR 6921, respectivamente ${ }^{11}$. Na Figura 1, é apresentada a foto dos coletores instalados na SE_Paripe, na altura dos isoladores trabalhados.

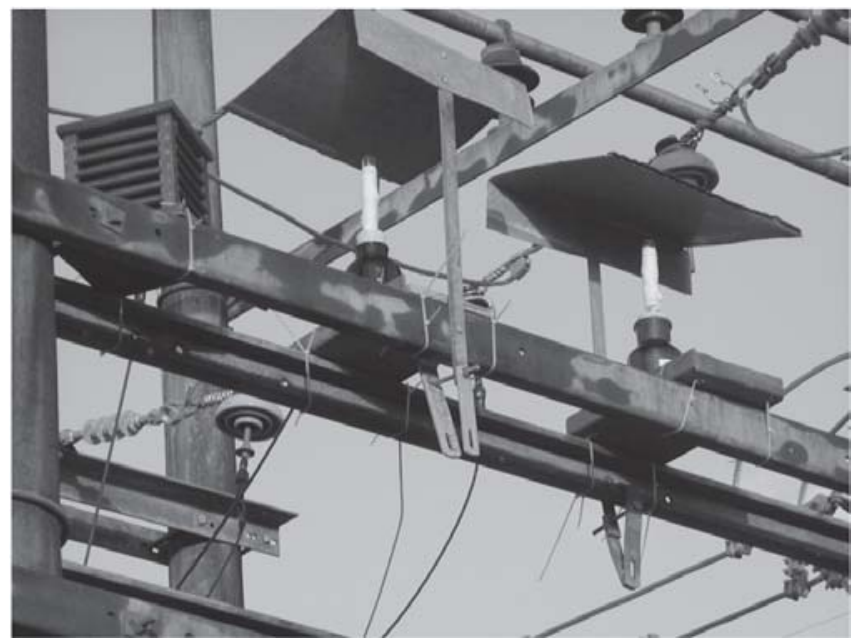

Figura 1. Coletores instalados na SE_Paripe: a) de cloretos (velas brancas); b) coletor de sulfato (instalado no interior da caixa de madeira em treliça)

\section{Análise de poluentes nos isoladores instalados na RD}

As amostras de isoladores foram retiradas periodicamente, em pontos localizados, sendo substituídos por novos, também identificados para análises programadas. Os locais de retirada foram escolhidos em função da frequiência de falhas da rede, sendo provenientes desde a orla da Baía de Aratu até a SE_Paripe e em pontos estratégicos localizados na região industrial da RMS.

\section{Coleta de dados atmosféricos na SE_Paripe}

Para a coleta de dados atmosféricos: temperatura, direção e velocidade dos ventos, umidade, pressão, precipitação e ponto de orvalho, foi utilizado o sistema de aquisição de dados meteorológicos "Eletronic Weather Station - Hunger", e o "software Skyview systems Weather View".

\section{Medidas de resistência de isolamento em isoladores}

Para a verificação do efeito dos poluentes depositados sobre a superfície dos isoladores foram feitos estudos de algumas propriedades elétricas dos mesmos, tais como a resistência de isolamento, a corrente de fuga em função do tempo e a descarga parcial.

As medidas de resistência de isolamento foram efetuadas entre a cabeça do isolador e o pino ou ferragem de sustentação. O equipamento utilizado para as medidas foi um medidor de altas resistênci- 
as marca Hewlett Packard, modelo 4339A e os testes foram realizados em ambiente controlado, na temperatura média de $20 \pm 2{ }^{\circ} \mathrm{C}$, com umidade média relativa de $60 \pm 2 \%$ e com a amostra inserida em gaiola de Faraday para evitar interferências eletromagnéticas. Foi aplicada tensão de $500 \mathrm{~V} \mathrm{DC}$, durante $60 \mathrm{~s}$. Terminado o período de aplicação de tensão a leitura foi efetuada e registrada. O objetivo desta medida foi verificar alterações na resistência de isolamento do dispositivo isolador com os poluentes aderidos na sua superfície.

Para as medidas da corrente de fuga e das descargas parciais nos isoladores submetidos à poluição atmosférica foi disponibilizada uma área dentro da SE_Paripe, onde foi instalada uma estação de teste mostrada na Figura 2. Os isoladores foram instalados, por meio de amarração convencional, a cabos de alumínio fixados em estruturas existentes na Subestação. Foram avaliados os desempenhos dos isoladores de porcelana, vidro e híbrido (capa de silicone), quanto à corrente de fuga e descarga parcial e em função do tempo de exposição aos poluentes atmosféricos in-situ.

(a)

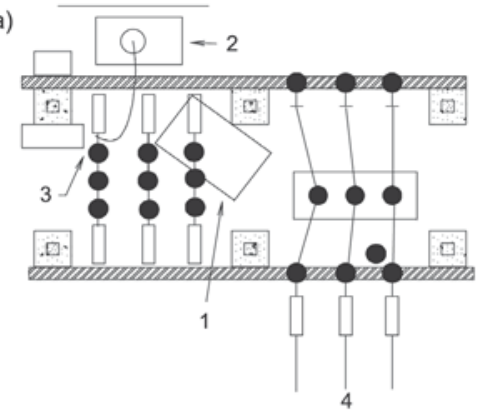

Legenda: 1_painel de medidores comunicação; 2 transformador; 3_isoladores sob teste; 4_alimentador.

(b)

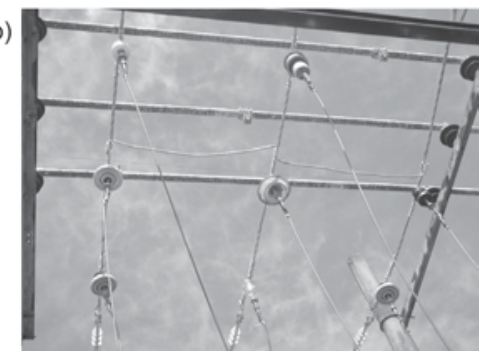

Figura 2. a) Diagrama da estação de testes da corrente de fuga e de descargas parciais nos isoladores na SE_Paripe; b) vista inferior da montagem dos isoladores

Os corpos-de-prova, CPs, foram submetidos à tensão fase-terra de $8 \mathrm{kV}$, fornecida por um transformador de distribuição alimentado pela baixa tensão.

As atividades de planejamento, registro, coleta, armazenamento e envio de dados foram elaboradas por intermédio de um sistema automatizado, conforme mostrado na Figura 3.

$\mathrm{O}$ isolador, energizado tal como na linha de $\mathrm{RD}$, foi aterrado por um cabo coaxial e um conjunto de resistores, permitindo a medição das correntes de fuga e das descargas ao longo do tempo de exposição ao meio. O sistema de medição foi acoplado a um computador industrial, no qual vêm sendo armazenadas as grandezas medidas. Estas são manipuladas e apresentadas na forma gráfica no próprio computador, permitindo acesso dos dados à distância (via remota) pela internet por um modem celular. A proteção do circuito foi realizada utilizando-se centelhadores e dispositivo de sobrecorrente, que desliga o transformador elevador. Ao computador industrial encontra-se conectada, também, a estação meteoro- a)

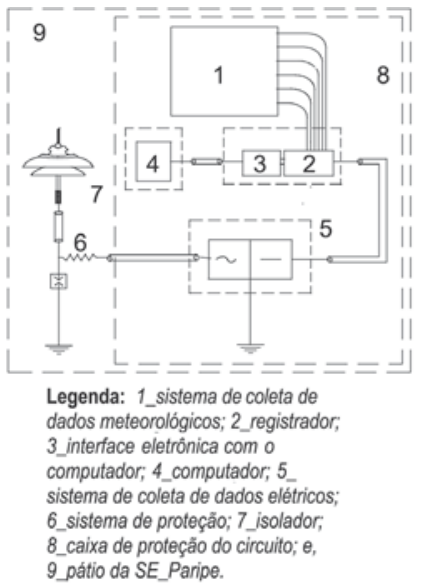

b)

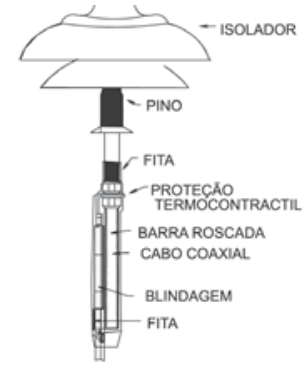

Figura 3. a) circuito eletrônico para a coleta de dados de corrente de fuga, descarga parcial e metereológicos; $b$ ) detalhe das conexões em um dos isoladores

lógica, cujos dados de saída são armazenados e apresentados nas formas gráficas.

Todo o sistema de captura dos dados em campo foi desenhado e construído de forma a analisar, simultaneamente, até 8 unidades de isoladores, bem como os parâmetros das condições atmosféricas locais (velocidade e direção dos ventos; pressão; umidade; índice de orvalho; índice de precipitação pluviométrica e, temperatura ambiente).

\section{Limpeza de isoladores}

Os isoladores cobertos com poluição foram submetidos aos testes preliminares de limpeza química em laboratório com ácido oxálico e com outro removedor de ferrugem comercial, codificado como RFC.

\section{Ácido oxálico ${ }^{12}$}

O ácido oxálico é um dos produtos convenientemente utilizados para a limpeza de poluentes, principalmente se o depósito é à base de óxido de ferro. A dissolução ocorre segundo a reação química apresentada na Equação 1.

$\mathrm{Fe}_{2} \mathrm{O}_{3}+6 \mathrm{H}_{2} \mathrm{C}_{2} \mathrm{O}_{4} \rightleftarrows 2 \mathrm{Fe}\left(\mathrm{C}_{2} \mathrm{O}_{4}\right)_{3}^{3-}+3 \mathrm{H}_{2} \mathrm{O}+6 \mathrm{H}^{+}$

$\mathrm{O}$ ácido oxálico $\left(\mathrm{H}_{2} \mathrm{C}_{2} \mathrm{O}_{4}\right)$ na sua forma pura apresenta-se na forma de sólido, medianamente solúvel em água. Para os testes executados, foi preparada solução a $50 \mathrm{~g} / \mathrm{L}$ de água deionizada.

Para certificar uma possível avaria ou falha elétrica proveniente deste procedimento, um isolador foi pendurado dentro de uma câmara de intemperismo, com o intuito de se medir a corrente de fuga quando a solução de ácido oxálico fosse aplicada. A solução foi aplicada com um borrifador manual, regulado para produzir um esguicho ao invés de névoa. Após, o isolador foi submetido à tensão de $8 \mathrm{kV}$ e a corrente de fuga medida de acordo com o procedimento já descrito.

Depois da medida da corrente de fuga, aguardou-se cerca de $1800 \mathrm{~s}$ para se efetuar o enxágüe do isolador com água de torneira. Este procedimento foi realizado com jatos d'água. Também foi adotada, nos casos onde foram observados resíduos remanescentes, a limpeza posterior na forma manual, com esponja e água.

O RFC, um produto comercial indicado para remover ferrugem de substratos ferrosos, na sua forma líquida, foi utilizado para ve- 
rificação da sua eficácia na retirada dos materiais poluentes incrustrados nos isoladores da RD. Seguiram-se os mesmos procedimentos de limpeza posterior, indicados para o ácido oxálico.

\section{Recobrimento de isolador de vidro com borracha de silicone}

Borrachas de silicone vulcanizadas à temperatura ambiente foram aplicadas em isoladores de vidro e porcelana como forma de reduzir sua molhabilidade e a corrente de fuga superficial, suprimindo as descargas disruptivas. A vantagem da borracha de silicone é que apresenta, também, a propriedade de recuperar sua hidrofobicidade (capacidade de repelir água) após a contaminação com material iônico ou particulado. O material trabalhado apresentouse na forma líquida e foi aplicado com pincel em três camadas consecutivas, com intervalo de aproximadamente $30 \mathrm{~min}$ entre demãos. Uma semana após a aplicação, uma pequena porção da cobertura de alguns isoladores testados foi arrancada para a determinação das espessuras das camadas obtidas de aproximadamente $200 \mu \mathrm{m}$. Prevendo-se que, na região da cabeça do isolador, os esforços mecânicos de compressão e atrito, gerados pelo cabo condutor e pela amarração metálica, poderiam causar danos à borracha, esta região não foi recoberta.

\section{Identificação e descrição dos isoladores estudados}

Os isoladores estudados foram escolhidos em função da sua quantidade em uso pela concessionária e pela freqüência dos problemas detectados. Os dados técnicos apresentados são provenientes das informações de catálogos dos respectivos fabricantes, referem-se ao isolador novo e estão reunidos na Tabela 1, sendo: 1) isolador de pino, tipo S57. Este isolador foi montado na posição 1 da estação de teste, sendo de porcelana marrom, envelhecido naturalmente em campo; 2) na posição 2 da estação de teste, foi montado isolador de pino, tipo 5058 (2005), novo, de porcelana cinza; 3) isolador de pino híbrido, tipo 5331; 4) e 5) isoladores de vidro, tipo pino VFO85, foram montados nas posições 4 e 5 , na condição de envelhecidos e poluídos; 6) isolador novo de vidro, tipo pino, re- vestido com borracha de silicone, foi montado na posição 6; 7) na posição 7, foi montado isolador de pino, tipo 5058 (2005), novo, de porcelana cinza revestida com borracha de silicone (as características técnicas referem-se ao isolador novo sem revestimento); e, 8) isolador pilar novo, PL-11253 (ANSI 57-2) foi montado na posição 8 , sendo de porcelana cinza.

\section{RESULTADOS E DISCUSSÃO}

Foi verificada sobre a superfície de um dos isoladores de vidro retirados por causa de falhas elétricas da RD uma camada de material particulado de tonalidade marrom avermelhada, similar ao de óxido de ferro, bastante aderente. Este material não foi retirado facilmente com auxílio de ferramentas metálicas manuais, por raspagem. Codificado como MP_1, tem o aspecto e a tonalidade similar ao do MP_3, que vem sendo descarregado e transportado periodicamente na região da Baía de Aratu. Este dois materiais mais o MP_2 (pó retido por filtragem na SE_Paripe) foram analisados comparativamente por EDS, distribuição granulométrica, propriedades ferromagnéticas e difratometria de raios X e apresentaram os resultados listados na sequiência.

\section{Propriedade ferromagnética}

Os testes foram qualitativos e os resultados positivos para as amostras MP_1, 2 e 3, conforme exemplificado na Figura 4 (o pó acompanhou a movimentação do imã pela superfície do frasco de vidro).

\section{Análise elementar e composição química}

Todas as amostras de material particulado contêm, tipicamente, ferro, sílica, oxigênio e alumínio (em maiores proporções em peso) e outros componentes em menor quantidade, conforme resultados listados na Tabela 2. O MP_3, apresentou, adicionalmente, o manganês em $12,9 \%$, o que se justifica pelo fato de haver descarregamentos periódicos de minérios de diferentes jazidas no local. $\mathrm{Na}$

Tabela 1. Isoladores submetidos a testes de correntes de fuga e descargas parciais na SE_Paripe, cada qual nas respectivas posições no barramento elétrico disponibilizado

\begin{tabular}{|c|c|c|c|c|c|c|c|c|c|}
\hline \multirow{2}{*}{\multicolumn{2}{|c|}{ Características do isolador }} & \multicolumn{8}{|c|}{ Valores de referência } \\
\hline & & 1 & 2 & 3 & 4 & 5 & 6 & 7 & 8 \\
\hline \multicolumn{2}{|l|}{ Tensão nominal, kV } & 15 & $15 / 25$ & 15 & $15 / 25$ & $15 / 25$ & 15 & $15 / 25$ & $25 / 35$ \\
\hline \multicolumn{2}{|l|}{ Distância de escoamento, mm } & 230 & 360 & 500 & 360 & 360 & 230 & 360 & 559 \\
\hline \multicolumn{2}{|l|}{ Distância de arco umido, mm } & - & - & - & 98 & 98 & - & - & - \\
\hline \multicolumn{2}{|l|}{ Distância de arco a seco, mm } & 145 & 159 & 145 & 154 & 154 & 145 & 159 & 241 \\
\hline \multicolumn{2}{|l|}{ Tensão suportável a seco, $\mathrm{kV}$} & 60 & 13,6 & - & - & - & - & - & - \\
\hline \multicolumn{2}{|c|}{ Tensão suportável sob chuva, kV } & 34 & 115 & 34 & - & - & - & - & - \\
\hline \multicolumn{2}{|l|}{ Perfuração sob óleo } & 95 & 140 & - & - & - & - & 115 & - \\
\hline \multirow{2}{*}{$\begin{array}{l}\text { Tensão crítica de } \\
\text { impulso }(1,2 \times 50) \mu \mathrm{s}\end{array}$} & Positiva, kV & 115 & 170 & - & - & - & - & 140 & 180 \\
\hline & Negativa, kV & 140 & 85 & - & - & - & - & 170 & 205 \\
\hline \multirow{2}{*}{$\begin{array}{l}\text { Tensão disruptiva à } \\
\text { freqüência industrial }(\mathrm{kV})\end{array}$} & Seco, kV & 70 & 45 & 75 & - & - & - & 85 & 110 \\
\hline & Sob chuva, kV & 45 & 15 & - & - & - & - & 45 & 85 \\
\hline \multirow{3}{*}{$\begin{array}{l}\text { Rádio interferência, } \\
\text { RI, a } 1000 \mathrm{kHz}(\mathrm{kV})\end{array}$} & Tensão de ensaio & 10 & 100 & - & - & - & - & 15 & 22 \\
\hline & TRI, máx. tratado & 5500 & 8000 & - & - & - & - & 100 & 100 \\
\hline & TRI, máx. normal & - & - & - & - & - & - & 8000 & - \\
\hline
\end{tabular}

Nota quanto aos isoladores: 1. porcelana, tipo pino S57, marrom, envelhecido naturalmente (1 ${ }^{\text {a }}$ posição na estação de testes); 2. porcelana, tipo 5058, novo, na cor cinza (2 $2^{a}$ posição); 3. tipo pino 5331, híbrido, novo (3 $3^{a}$ posição); 4 e 5. vidro, tipo pino VFO85, envelhecido naturalmente no campo (4 e $5^{\mathrm{a}}$ posições); 6. vidro, tipo pino, revestido com borracha tipo silicone (6 posição); 7. porcelana, tipo 5058, novo, na cor cinza, revestido com borracha de silicone (7a posição); 8. porcelana, tipo pilar, novo, na cor cinza (8ª posição). 


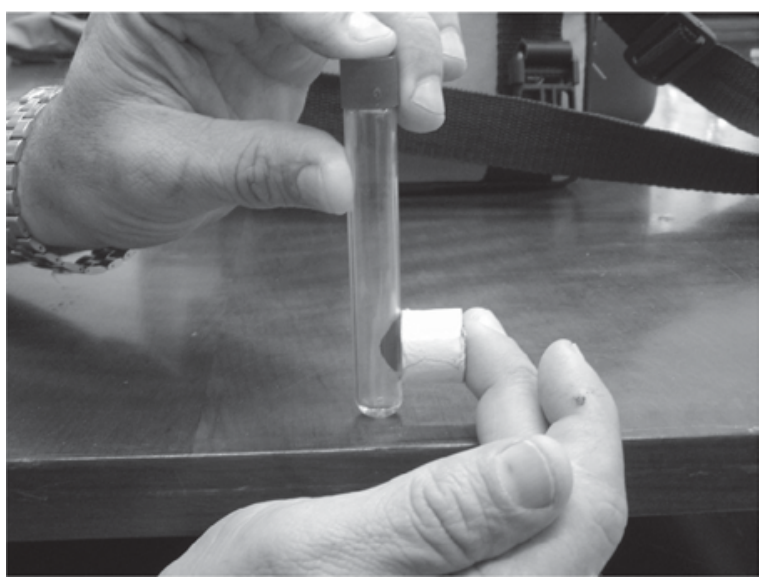

Figura 4. Imagem do teste da propriedade ferromagnética do pó retirado da saia dos isoladores da SE_Paripe. Resultado positivo

amostra MP_2 foram encontrados sódio e outros componentes químicos provenientes do papel de filtro. Apesar da similaridade nos resultados, não se pode atribuir que o material depositado sobre os isoladores foi proveniente única e exclusivamente do minério descarregado e transportado a partir da Baía de Aratu.

Tabela 2. Composições químicas semi-quantitativas (\% p/p) das amostras de pó: MP_1, MP_2 e MP_3, obtidas por EDS

\begin{tabular}{lccc}
\hline Elemento & $\begin{array}{c}\text { Amostra } \\
\text { MP_1 }(\% \mathrm{p} / \mathrm{p})\end{array}$ & $\begin{array}{c}\text { Amostra } \\
\text { MP_2 }(\% \mathrm{p} / \mathrm{p})\end{array}$ & $\begin{array}{c}\text { Amostra } \\
\text { MP_3 }(\% \mathrm{p} / \mathrm{p})\end{array}$ \\
\hline $\mathrm{Fe}$ & 57,10 & 8,37 & 51,81 \\
$\mathrm{O}$ & 24,95 & 32,27 & 23,13 \\
$\mathrm{Al}$ & 12,05 & 6,48 & 7,24 \\
$\mathrm{Mn}$ & $*$ & - & 12,9 \\
$\mathrm{Si}$ & 4,38 & 29,95 & 3,50 \\
$\mathrm{~S}$ & 0,67 & - & $*$ \\
$\mathrm{P}$ & 0,53 & - & 0,18 \\
$\mathrm{C}$ & 0,31 & 0,72 & 0,17 \\
$\mathrm{Ti}$ & $*$ & 1,14 & 0,70 \\
$\mathrm{~K}$ & $*$ & 2,40 & 0,35 \\
$\mathrm{Na}$ & $*$ & 11,67 & $*$ \\
$\mathrm{Ca}$ & $*$ & 5,38 & $*$ \\
Outros & 0,01 & 1,62 & 0,02 \\
\hline
\end{tabular}

*refere-se a uma concentração abaixo do limite de detecção do EDS ou ausente.

Pela difratometria de raios $\mathrm{X}$ foram obtidos os difratogramas mostrados na Figura 5, provenientes dos pós de materiais particulados (Pó_filtro de ar, correspondente ao MP_2); do minério (Pó_minério= MP_3) e dos depósitos superficiais aos isoladores (Pó_saia do isolador, MP_1). Verificou-se a similaridade entre o MP_2 e os poluentes depositados ao longo do tempo nas saias dos isoladores MP_1. O MP_3 apresentou fases químicas adicionais à base de Mn, cujo teor, semi-quantitativo, está apresentado na Tabela 2. Também, pelo estudo comparativo no banco de dados do "Joint Committee on Powder Diffraction Standard", JCPDS, pode-se concluir pela presença de sais de ferro (magnetita), sílica e materiais argiláceos, todos em maior proporção quantitativa nas amostras analisadas. Tais resultados corroboraram com o efeito ferromagnético observado qualitativamente, principalmente, quanto à identificação da magnetita.

\section{Medida da distribuição do tamanho médio das partículas do pó}

As distribuições granulométricas dos tamanhos médios das par-

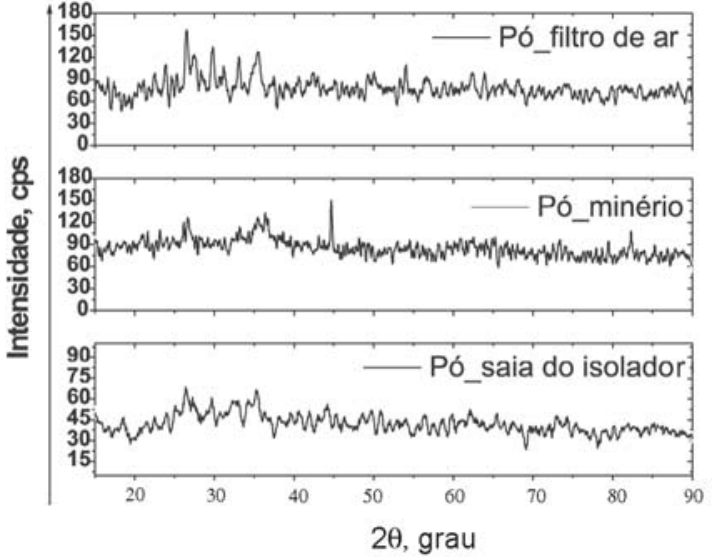

Figura 5. Difratogramas de raios $X$ : a) Pó_saia do isolador, $M P_{-}$; $b$ ) Pó_minério, MP_3; c) Pó_filtro de ar, MP_2

tículas do pó MP_1 e do pó de minério MP_3 foram de 78 e $14 \mu \mathrm{m}$, respectivamente. Para o MP_1, pode ter havido aglomeração das partículas em virtude do efeito conjugado da eletricidade com o calor e umidade ambientes, sendo difícil de desagregar sem um processo mecânico intenso e preliminar à análise. A amostra MP_2 não foi analisada por este método, pela dificuldade de desaglomeração e retirada do material impregnado no papel de filtro.

Destacaram-se como resultados importantes desta análise os fatos de que a distribuição granulométrica média das partículas do minério de ferro (amostra MP_3) foi $<30 \mu \mathrm{m}$. Partículas com tais diâmetros, quando lançadas na atmosfera, não sedimentam, podendo permanecer em suspensão por vários dias. Estas partículas em suspensão se aderem à superfície dos isoladores energizados por forças eletrostáticas, produzindo ao longo do tempo, por meio de sinterização, uma camada sólida bastante estável mecanicamente. Uma característica, também observada neste mecanismo de poluição, foi que a deposição ocorreu tanto nas superfícies superiores das saias dos isoladores quanto nas inferiores, inclusive nas suas reentrâncias.

Pelas características físico-químicas dos pós MP_1, MP_2 e MP_3, pode-se concluir que estes materiais particulados têm similaridade, principalmente, devido à magnetita identificada pela difratometria de raios $\mathrm{X}$.

Os resultados obtidos nas medidas da resistência de isolamento dos isoladores, com e sem poluição aderida, reduziram em até 3 ordens de grandeza pela presença de depósitos de poluentes e quando úmidos, como foi o caso dos isoladores de vidro, cuja resistência de isolamento no seu estado limpo ou novo foi de $2 \times 10^{11} \Omega$, passando para $2 \times 10^{10} \Omega$ com o poluente seco e para $3 \times 10^{9} \Omega$, após a umidificação artificial em laboratório ${ }^{13}$.

Os processos de limpeza efetuados para remoção dos depósitos de poluição foram efetivos, principalmente após utilizar o RFC. Na Figura 6, estão apresentados os gráficos da corrente de fuga (mA) versus o tempo (min), para um isolador em três situações distintas: com a camada de poluição, ou seja, depois de retirado da $\mathrm{RD}$; parcialmente limpo, depois da $1^{\mathrm{a}}$ lavagem química e, completamente limpo, após uma 2a lavagem. As medidas foram efetuadas sob nebulização contínua com água deionizada (névoa limpa). Constatou-se que o processo de limpeza com o RFC foi efetivo, reduzindo a corrente de fuga resultante. Tais respostas indicam poder postergar a substituição dos mesmos, diminuindo-se, assim, os custos de manutenção da RD. Observa-se na Figura 6, também, que à medida que as partículas aderidas na superfície do isolador foram umidecendo ocorreu um aumento no resultado da corrente de fuga, corroborando com o comentado na literatura ${ }^{3}$. 


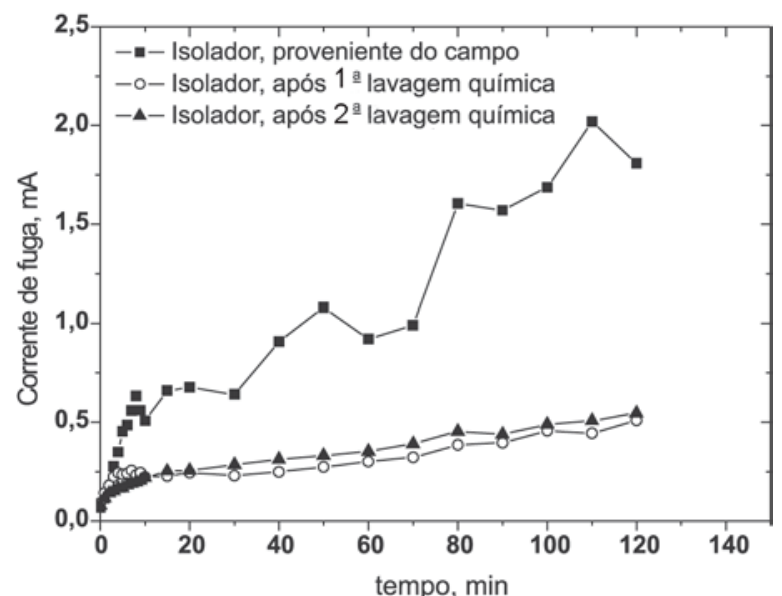

Figura 6. Correntes de fuga medidas sob névoa limpa: a) do isolador como retirado da $R D ; b)$ após uma primeira lavagem; c) após segunda lavagem com procedimento manual para a retirada dos poluentes

Fotos mostrando a efetividade do processo de limpeza dos isoladores podem ser visualizadas na Figura 7, sendo: o isolador como retirado da $\mathrm{RD}$ (completamente opaco); após uma primeira lavagem (isolador com menor opacidade) e, depois da $2^{\mathrm{a}}$ e última lavagem com procedimento manual de limpeza (saia do isolador mais transparente).

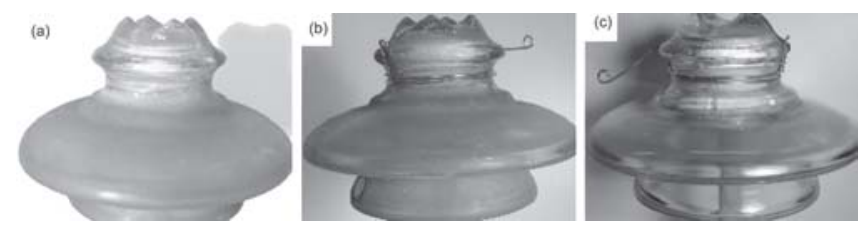

Figura 7. Isolador de vidro: a) como retirado da RD; b) após uma primeira lavagem com RFC; c) após a segunda lavagem, com procedimento manual para a retirada dos poluentes depositados

O uso do ácido oxálico como agente de limpeza química dos isoladores pareceu ser limitado por três razões: devido a sua toxidez; ser altamente corrosivo e, por produzir corrente de fuga maior que o do RFC, inviabilizando o processo de limpeza em linha viva.

Na Figura 8, encontra-se um gráfico da corrente de fuga de um dos isoladores de vidro instalados na SE_Paripe (as características técnicas são visualizadas na Tabela 1), obtido no mês de outubro de 2006, para um isolador de vidro com poluição natural deposita- da em sua superfície. Observou-se que os pontos de máximo em corrente de fuga corresponderam ao período da madrugada, quando a umidade relativa do ar atingiu valores próximos de $90 \%{ }^{13}$. Entre 6 e $7 \mathrm{~h}$ da manhã, começou a ocorrer a secagem superficial pela ação do sol, de forma que a corrente elétrica caiu rapidamente.

Também pode ser observado no gráfico que houve um aumento da corrente de fuga nos períodos de chuva. Como o material particulado estava firmemente aderido à superfície do isolador, as chuvas não o eliminaram e, por isso, não foi constatada nenhuma diminuição perceptível nos valores de corrente de fuga após a ocorrência das mesmas. Ficou, neste caso, confirmada a necessidade de intervenção para manutenção periódica de isoladores poluídos, com um processo de lavagem, a fim de que sejam minimizados o efeito de falhas elétricas e os riscos de "apagão".

Na Tabela 3, estão apresentadas as quantidades de descargas parciais registradas durante novembro/2006 e janeiro/2007. As quantidades de descargas estão agrupadas dentro de três patamares de corrente, sendo entre 0,1 e $0,2 \mathrm{~mA}$ aquelas que ocorreram com maior frequiência. Os isoladores 4,5 e 6 (Tabela 1 - (posições 4 e 5)) foram os que apresentaram o maior $\mathrm{n}^{\mathrm{o}}$ de descargas parciais elétricas com valores entre 0,2 e 0,3 mA. Estes mesmos isoladores apresentaram quantidades significativas de descargas entre 0,3 e $0,4 \mathrm{~mA}$.

É interessante comparar os resultados obtidos para os isoladores 2 e 6, que são do mesmo tipo, mas com o de no 6 tendo sido revestido com borracha de silicone. Este último exibiu uma quantidade de descargas parciais menor, nos três períodos analisados, demonstrando a efetividade do revestimento, principalmente quanto à sua hidrofobicidade.

Entre os meses de novembro e dezembro de 2006 não houve, praticamente, modificação no comportamento elétrico dos isoladores, como se pode verificar pelos valores similares de descargas parciais exibidos nos períodos. No mês de janeiro de 2007 observou-se um aumento de 30 a $45 \%$ na quantidade de descargas parciais, com relação ao mês anterior, coincidindo com um maior período de precipitação pluviométrica local, tal como constatado para o mês de novembro de $2006^{13}$.

\section{Poluentes atmosféricos ${ }^{13}$}

Os valores médios dos poluentes atmosféricos medidos pelo íon cloreto e pela taxa de sulfatação no período de 5 meses foram de $19 \pm 6 \mathrm{mg} / \mathrm{m}^{2}$.dia de cloreto e de $13 \pm 5 \mathrm{mg} / \mathrm{m}^{2}$.dia de dióxido de enxofre. Foram inferiores ao limite estabelecido para classificar o

Tabela 3. Quantidade de descargas parciais em isoladores instalados na SE_Paripe, BA, registrada durante os meses de novembro de 2006 a janeiro de 2007

\begin{tabular}{|c|c|c|c|c|c|c|c|c|c|}
\hline \multirow[b]{2}{*}{$\mathrm{mA}$} & \multirow[b]{2}{*}{$\begin{array}{c}\text { Patamares } \\
\text { de corrente, }\end{array}$} & \multicolumn{7}{|c|}{ Isolador } & \multirow[b]{2}{*}{8} \\
\hline & & 1 & 2 & 3 & 4 & 5 & 6 & 7 & \\
\hline \multirow[t]{4}{*}{ Novembro 2006} & $0,1-0,2$ & 21.266 & 28.711 & 25.164 & 34.182 & 27.187 & 29.202 & 17.137 & 26.014 \\
\hline & $0,2-0,3$ & 340 & 1.067 & 663 & 4.805 & 3.897 & 1.417 & 229 & 660 \\
\hline & $0,3-0,4$ & 2 & 11 & 6 & 752 & 201 & 341 & 1 & 4 \\
\hline & Total & 21.609 & 29.791 & 25.836 & 39.743 & 31.290 & 30.966 & 17.374 & 26.686 \\
\hline \multirow[t]{4}{*}{ Dezembro 2006} & $0,1-0,2$ & 18.088 & 25.693 & 22.411 & 35.318 & 28.233 & 26.984 & 14.841 & 23.125 \\
\hline & $0,2-0,3$ & 106 & 483 & 266 & 2.858 & 2.101 & 608 & 71 & 269 \\
\hline & $0,3-0,4$ & 0 & 3 & 0 & 67 & 58 & 7 & 0 & 1 \\
\hline & Total & 18.194 & 26.194 & 22.677 & 38.243 & 30.392 & 27.599 & 14.912 & 23.395 \\
\hline \multirow[t]{4}{*}{ Janeiro 2007} & $0,1-0,2$ & 26.225 & 33.448 & 32.321 & 46.862 & 36.800 & 37.102 & 21.759 & 33.372 \\
\hline & $0,2-0,3$ & 182 & 596 & 417 & 4.664 & 2.115 & 885 & 134 & 394 \\
\hline & $0,3-0,4$ & 0 & 8 & 4 & 178 & 110 & 15 & 1 & 1 \\
\hline & Total & 26.407 & 34.052 & 32.742 & 51.704 & 39.025 & 38.002 & 21.894 & 33.767 \\
\hline
\end{tabular}




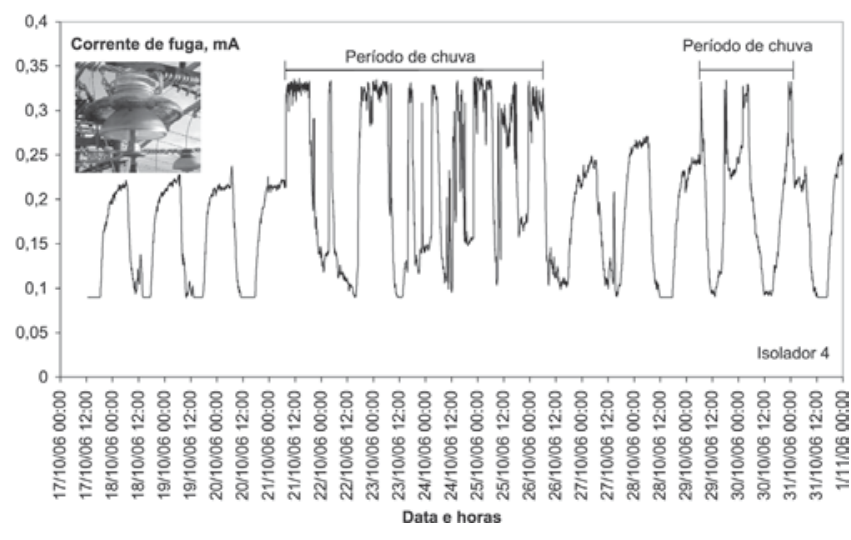

Figura 8. Corrente de fuga ( $m A$ ) no isolador 4 (isolador de vidro) instalado na estação de testes da SE_Paripe, Ba. Valores registrados durante o mês de outubro de 2006

ambiente como marinho ou mesmo industrial, ficando dentro do limite de uma atmosfera rural, sendo $<30 \mathrm{mg} / \mathrm{m}^{2}$.dia para o íon cloreto e entre 9,60 e $29,61 \mathrm{mg} / \mathrm{m}^{2}$.dia para o $\mathrm{SO}_{2}$, segundo Liesegang apud Kenny ${ }^{13}$.

Quanto à taxa de corrosão, o ambiente local pode ser classificado como $\mathrm{t}_{4}$ (de alta taxa) devido ao número de horas anuais de tempo de superfície úmida. Utilizando-se a classificação da NBR $14643^{1}$, quanto aos íons cloreto (B) e a taxa de sulfatação (A), o ambiente da SE_Paripe foi considerado como $\left(\mathrm{A}_{1}, \mathrm{~B}_{1}, \mathrm{t}_{4}\right)$, ou seja, de média corrosividade $\left(\mathrm{C}_{3}\right)$ para os metais aço-carbono, zinco, cobre e alumínio. Não há dados relativos ao efeito dessa categoria de corrosividade sobre os isoladores da RD, porém, estudos da literatura indicam que vidros e vidrados são influenciados pelo meio ambiente corrosivo ${ }^{14}$.

\section{CONCLUSÕES}

A Baía de Aratu, BA, especificamente na região da SE_Paripe e arredores (cerca de $2 \mathrm{~km}^{2}$ ), pode ser considerada como pertencentes a um ambiente com alta taxa de corrosão, devido ao seu tempo de superfície úmida, $\mathrm{t}_{4}$, e de média corrosividade, $\mathrm{C}_{3}$, quando avaliado em função dos metais de engenharia: aço-carbono, zinco, cobre e alumínio. A atmosfera local pode ser considerada como rural, quanto à salinidade e à taxa de sulfatação medidas pelos métodos da vela úmida e do dióxido de chumbo.

Considerando-se os efeitos deletérios sobre os isoladores da RD local, puderam-se atribuir tais falhas como consequientes, também, dos depósitos de materiais particulados presentes no ar atmosférico e cuja fase cristalina principal foi a magnetita. Esta fase cristalina se mostrou extremamente aderente às saias dos isoladores, sendo removida, somente por processos manuais de limpeza com esponja, removedor químico e água.

A corrente de fuga e a descarga parcial medidas nos isoladores energizados foram técnicas conclusivas do efeito da poluição devida aos depósitos de poluentes. A técnica permitiu evidenciar as maiores perdas elétricas, inferindo a possibilidade de surtos do sistema de energia nos períodos noturnos, quando houve maior concentração de umidade e, também, nos períodos chuvosos.

Os processos de limpeza com removedores de poluentes à base de óxidos de ferro, lavagens posteriores com jatos d'água e remoção manual do restante do material particulado aderido demonstraram serem efetivos, ampliando a necessidade de substituição dos isoladores devida à poluição atmosférica, bem como diminuindo a incidência de perdas elétricas.
O emprego de revestimento à base de silicone demonstrou, apesar do curto período de análise, ser eficaz na redução do número de eventos elétricos registrados. Tal fato foi atribuído à sua hidrofobicidade. Pouco material particulado ficou aderido à sua superfície.

Dentre os tipos de isoladores estudados destacaram-se, quanto ao desempenho, o isolador híbrido, principalmente pela maior distância de escoamento e sua saia de silicone em formato de duplo sino, seguido pelo isolador tipo pilar de porcelana, também pela maior distância de escoamento. Os piores desempenhos foram constatados para os isoladores de vidro. Considerando-se o melhor desempenho em função da distância de escoamento, destacou-se o isolador tipo pino de porcelana, que ficou em segundo lugar na classificação.

Finalmente, pode-se considerar que a metodologia serviu para predizer os eventos elétricos que ocorreram sobre os isoladores da RD local, sendo, então, considerada uma alternativa viável para a constatação de falhas em áreas de alta poluição. Neste caso, recomenda-se utilizar tal modelo como isoladores "mestres". Estes, seriam instalados em locais de alta poluição, servindo como "sensores" ou mesmo "detetores" de falhas elétricas.

\section{AGRADECIMENTOS}

À COELBA, ao LACTEC e à ANEEL, pela confiança, infraestrutura e apoio financeiro para a execução deste projeto de pesquisa.

\section{REFERÊNCIAS}

1. http://www.emtursa.ba.gov.br/Template.asp?nivel=00010006\&identidade=12, acessada em Fevereiro 2007; ABNT NBR 14643; Corrosão atmosférica, classificação da corrosividade de atmosferas, Rio de Janeiro, 2001.

2. Sillars, R. W.; Electrical insulating material and their application, IEE Monograph Series 14, Peter Peregrinus: England, 1973; Looms, J. S. T.; Insulators for high voltage, Peter Peregrinus: London, 1988; IEC 815: Guide for the selection of insulators in respect of polluted conditions, 1986, Switzerland.

3. Usui, W.; Kasuya, N.; Osaka, H.; Ito, S.; Kurebayashi, H.; Matsuoka, R.; Proceedings of the $6^{\text {th }}$ International Conference on Properties and Applications of Dielectric Materials, Xi' an, China, 2000; Matsuoka, R.; Naito, K.; Irie, T.; Kondo, K.; T\&D Ásia Pacific 2002, 2197.

4. Shaowu, W; Xidong, L.; Lengceng, H.; IEEE Conference on Electrical Insulation and Dielectric Phenomena, Beijing, China 1999; Naito, K.; Izumi, K.; Takusu, K.; Matsuouka, R.; 36 $6^{\text {th }}$ CIGRE Session Discussion Proceedings, Paris, France, 1996.

5. Ishiwari, M.; Ito, S.; Arakawa, K.; Nakachi T.; Kondo, K.; Proceeding of $11^{\text {th }}$ High Voltage Engineering Symposium, London, UK, 1999.

6. Delgado, M. P.; Insulator News \& Market Report 2000, 8, 518.

7. Sörqvist, T.; Vlastós, A.; IEEE International Symposium on Electrical Insulation, Canada, 1996; Vlastós, A. E.; Proceedings of the $4^{\text {th }}$ International Conference on Properties and Applications of Dielectric Materials, Australia, 1994.

8. http://www.naturlink.pt/canais/Artigo.asp?iArtigo=11316\&iLingua=1, acessada em Fevereiro 2007.

9. Malik, N. H.; Al-Arainy, A. A.; Qureshi, M. I.; Electrical insulation in power systems, Marcel Dekker: New York, 1998.

10. ABNT NBR 9547; Material particulado em suspensão no ar ambientedeterminação da concentração total pelo método do amostrador de grande volume, Rio de Janeiro, 1997.

11. ABNT NBR 6211; Determinação de cloretos na atmosfera pelo método da vela úmida, 2001, Rio de Janeiro; ABNT NBR 6921; Sulfatação total na atmosfera - determinação da taxa pelo método da vela de dióxido de chumbo, 1981, Rio de Janeiro.

12. http://alsnetbiz.com/homeimprovement/oxalic_acid.html, acessada em Fevereiro 2007.

13. Portella, K. F.; Inone, P. C.; Piazza, F.; Ribeiro, S; Relatório técnico de projeto, LACTEC/COELBA_ANEEL, 2007; Kenny, E. D.; Cruz, O. M.; Silva, J. M.; Sica, Y. C.; Ravaglio, M.; Mendes, P. R.; Mendes, J. C.; Relatório técnico LACTEC, 2005.

14. Ziemath, E. C.; Quim. Nova 1998, 21, 356. 